\title{
Low incidence of ABL-class and JAK-STAT signaling pathway alterations in uniformly treated pediatric and adult B-cell acute lymphoblastic leukemia patients using MRD risk-directed approach - a population- based study
}

Rimvydas Norvilas ${ }^{12^{*}}$ (D), Vaidas Dirse ${ }^{1,3}$, Ruta Semaskeviciene ${ }^{1}$, Orinta Mickeviciute ${ }^{1}$, Egle Gineikiene ${ }^{1}$, Mindaugas Stoskus ${ }^{1}$, Goda Vaitkeviciene ${ }^{3,4}$, Jelena Rascon ${ }^{3,4}$ and Laimonas Griskevicius ${ }^{1,3}$

\begin{abstract}
Background: ABL-class and JAK-STAT signaling pathway activating alterations have been associated with both a poor post-induction minimal residual disease (MRD) response and an inferior outcome in B-cell acute lymphoblastic leukemia (B-ALL). However, in most of the studies patients received non-uniform treatment.

Methods: We performed a population-based analysis of 160 (122 pediatric and 38 adult) Lithuanian BCR-ABL1negative B-ALL patients who had been uniformly treated according to MRD-directed NOPHO ALL-2008 protocol. Targeted RNA sequencing and FISH analysis were performed in cases without canonical B-ALL genomic alterations (high hyperdiploids and low hypodiploids included).

Results: We identified ABL-class fusions in 3/160 (1.9\%) B-ALL patients, and exclusively in adults $(p=0.003)$. JAKSTAT pathway fusions were present in 4/160 (2.5\%) cases. Of note, P2RY8-CRLF2 fusion was absent in both pediatric and adult B-ALL cases. Patients with ABL-class or JAK-STAT pathway fusions had a poor MRD response and were assigned to the higher risk groups, and had an inferior event-free survival (EFS) / overall survival (OS) compared to patients without these fusions. In a multivariate analysis, positivity for ABL-class and JAK-STAT fusions was a risk factor for worse EFS $(p=0.046)$ but not for OS $(p=0.278)$ in adults.
\end{abstract}

Conclusions: We report a low overall frequency of ABL-class and JAK-STAT fusions and the absence of P2RY8-CRLF2 gene fusion in the Lithuanian BCR-ABL1 negative B-ALL cohort. Future (larger) studies are warranted to confirm an inferior event-free survival of ABL-class/JAK-STAT fusion-positive adult patients in MRD-directed protocols.

Keywords: B-ALL, ABL-class, JAK-STAT, RNA-Seq

\footnotetext{
* Correspondence: rimvydas.norvilas@santa.lt

'Hematology, Oncology and Transfusion Medicine Center, Vilnius University Hospital Santaros Klinikos, Vilnius, Lithuania

${ }^{2}$ Department of Experimental, Preventive and Clinical Medicine, State Research Institute Centre for Innovative Medicine, Vilnius, Lithuania Full list of author information is available at the end of the article
}

C C The Author(s). 2021 Open Access This article is licensed under a Creative Commons Attribution 4.0 International License, which permits use, sharing, adaptation, distribution and reproduction in any medium or format, as long as you give appropriate credit to the original author(s) and the source, provide a link to the Creative Commons licence, and indicate if changes were made. The images or other third party material in this article are included in the article's Creative Commons licence, unless indicated otherwise in a credit line to the material. If material is not included in the article's Creative Commons licence and your intended use is not permitted by statutory regulation or exceeds the permitted use, you will need to obtain permission directly from the copyright holder. To view a copy of this licence, visit http://creativecommons.org/licenses/by/4.0/. The Creative Commons Public Domain Dedication waiver (http://creativecommons.org/publicdomain/zero/1.0/) applies to the data made available in this article, unless otherwise stated in a credit line to the data. 


\section{Background}

B-cell acute lymphoblastic leukemia (B-ALL) is an aggressive and genetically heterogeneous disease which mostly affects children and young adults [1]. A number of genomic alterations has been associated with the BALL outcome resulting in risk-adapted treatment protocols [2]. Approximately one-third of both pediatric and adult B-ALL cases do not harbor any canonical genomic alterations [3]. Gene expression profiling (GEP) of patients negative for canonical B-ALL alterations identified a subgroup of cases characterized by a similar expression profile to those harboring $\mathrm{t}(9 ; 22)$ (q34; $\mathrm{q} 11) / B C R-A B L 1$ (Philadelphia chromosome-like (Ph-like) or BCR-ABL1like B-ALL) $[4,5]$.

Whole transcriptome/exome sequencing and fluorescence in situ hybridization (FISH) analysis of Ph-like BALL samples revealed high frequency of genomic alterations disrupting the normal function of kinase and cytokine receptor signaling pathways of which ABL-class kinase and JAK-STAT signaling pathway genes were the most commonly affected [6]. ABL-class gene and JAKSTAT pathway alterations are associated with high postinduction MRD levels, an increased relapse rate and inferior outcome. Of note, some of these gene fusions can be successfully targeted using small-molecule inhibitors [7-12]. The identification of a Ph-like B-ALL signature is not standardized and both ABL-class and JAK-STAT fusions can also be found outside of the Ph-like B-ALL group [13-16]. High expression levels of the CRLF2 gene and $I K Z F 1$ gene deletions are also common in the Ph-like B-ALL subgroup resulting in a worse outcome in some series $[5,17]$.

In most studies, a Ph-like B-ALL was clinically characterized as a high-risk group with inferior overall survival in intensively treated children and adults [18-20]. In contrast, Ph-like B-ALL children did not have inferior survival when a minimal residual disease (MRD)-directed treatment of Total Therapy XV protocol was used $[21,22]$. Whether MRD-directed treatment can also improve the negative prognosis of Ph-like B-ALL adult patients remains to be defined.

In this study we performed a comparative genomic and clinical data analysis of pediatric and adult B-ALL patients to characterize the incidence of ABL-class and JAK-STAT signaling pathway activating alterations in the Lithuanian population and to determine their clinical significance in a MRD-risk directed treatment setting.

\section{Methods}

\section{Patients and samples}

From July 2008 to December 2017, pediatric (1-17 year-olds) and adult (18-45 year-olds) B-ALL patients who had been diagnosed with $B C R-A B L 1$-negative $\mathrm{B}$ ALL in Lithuania and enrolled into a NOPHO ALL-
2008 clinical trial [2] were included. In addition, eleven 46-65 year-old adult patients were treated according to a NOPHO ALL-2008 protocol with a chemotherapy dose modification and outside of the clinical trial. The patients' data were collected retrospectively.

The diagnosis of ALL was based on a bone marrow biopsy or aspirate showing $\geq 20 \%$ leukemic blasts. The protocol specific genomic analysis was limited to canonical B-ALL genomic alterations - $\mathrm{t}(12 ; 21) / E T V 6-$ RUNX1, t(1;19)/TCF3-PBX1, 11q23/KMT2A gene rearrangements, iAMP21, dic $(9 ; 20)$, high hyperdiploidy (5167 chromosomes) and low hypodiploidy (31-39 chromosomes). Cases without canonical B-ALL translocations were selected for RNA sequencing. Patients with ploidy shifts (high hyperdiploidy or low hypodiploidy) were also selected for RNA sequencing as they could harbor additional kinase and cytokine receptor signaling pathway alterations [23, 24].

Patients were stratified to the three risk groups defined in the NOPHO ALL-2008 protocol detailed elsewhere [2]. Stratifying factors were white blood cell count, immunophenotype and cytogenetic markers at diagnosis and treatment response defined as MRD. High genetic risk was assigned if $K M T 2 A$ gene rearrangements, iAMP21, dic $(9 ; 20)$ or low hypodiploidy were present. The MRD analysis was performed on days 15, 29 and 79 (only for standard risk (SR) and intermediate risk (IR) patients) or after each block (in high-risk (HR) arm until MRD-negativity). If MRD was $\geq 0.1 \%$ on day 79 (SR and IR) or after block B1 (HR), patients were referred to an allogeneic hematopoietic stem cell transplant (SCT) after receiving at least one additional block of therapy and having MRD below $<0.1 \%$ (optimally negative) (HR-SCT arm).

The study was conducted in accordance with the Declaration of Helsinki, and the protocol was approved by the Vilnius Regional Bioethics Committee. The patients provided written informed consent. The waiver for obtaining written informed consent from patients who could not be reached despite our best efforts was approved by the Vilnius Regional Bioethics Committee according to national regulations.

\section{RNA purification and targeted RNA-sequencing}

Total RNA was purified from fresh bone marrow samples at the time of diagnosis using silica-membranebased purification protocols and stored at $-80{ }^{\circ} \mathrm{C}$. All bone marrow samples had blast counts $\geq 70 \%$. Before RNA sequencing (RNA-Seq), purified RNA concentration and quality was assessed using NanoDrop2000 spectrophotometer.

RNA-Seq libraries were constructed using the Illumina TruSight Pan-Cancer sequencing kit (Illumina, San Diego, CA, USA), following the manufacturer's protocol 
and recommendations. The libraries were sequenced using Illumina MiSeq genome analyzer (Illumina). A total of 1385 cancer-related genes were analyzed including frequently mutated genes of ABL-class $(A B L 1, A B L 2$, PDGFRB, CSF1R) and JAK-STAT (JAK1, JAK2, JAK3, $C R L F 2)$ signaling pathways. At least 4 million paired-end reads were obtained for each sample. NGS data analysis was performed using the Illumina BaseSpace Informatics Suite (Illumina). TopHat/STAR aligners and a Manta fusion caller were used to detect novel and recurrent gene fusions. At least one partner gene was required to detect novel gene fusion. Only high-confidence fusions were called that met threshold filters: split and paired unique reads ( $\geq 3$ ), fusion contig align ( $\geq 16$ bp in length), coverage after fusion ( $\geq 100 \mathrm{bp})$, break end homology ( $\leq 10 \mathrm{bp})$.

Additional gene mutation analysis from RNA-Seq data was performed using the GATK pipeline and Isaac Variant Caller 2.3. Point mutations and small indels were called if they had an allele frequency $\geq 5 \%$ and a population frequency $<0.01$, were negative for known SNP's and were previously described in genomic variant databases (COSMIC, ClinVar, OMIM, HGMD).

Prior to the study, the RNA-Seq method was first validated using thirteen B-ALL control samples with previously identified gene fusions $(B C R-A B L 1 n=5, K M T 2 A$ gene rearrangements $\mathrm{n}=5$, TCF3-PBX1 $n=2$, ETV6RUNX1 $n=1)$. All in-frame gene fusions were identified, therefore the RNA-Seq method was used for B-ALL study patients.

\section{FISH, PCR and SNP Array data analysis of B-ALL fusions}

Due to technical limitations of RNA-Seq, additional FISH analysis of CRLF2 gene (CRLF2 (Xp22/Yp11) Break / IGH Fusion,TC; Leica Biosystems, Wetzlar, Germany) was performed to identify P2RY8-CRLF2 and $I G H-C R L F 2$ gene fusions. FISH analysis for $A B L 1$ (SPEC $A B L 1$ Dual Color Break Apart Probe; ZytoVision, Bremerhaven, Germany), ABL2 (SPEC ABL2 Dual Color Break Apart Probe; ZytoLight), JAK2 (JAK2 (9p24) Break; Leica Biosystems) and PDGFRB (PDGFRB (5q32) Break; Leica Biosystems) genes were used to confirm respective gene fusions detected by the RNA-Seq method. FISH analysis was performed according to manufacturer protocols.

Standard RT-PCR followed by a gel electrophoresis and Sanger sequencing were used to confirm in-frame fusions that were not confirmed with an additional FISH analysis. Fusion specific PCR primers were constructed for each case (Additional file 1: Table S1).

P2RY8-CRLF2 fusion is a result a of $320 \mathrm{~Kb}$ size deletion of the PAR1 region in the short arm of either $\mathrm{X}$ or Y chromosomes. We performed SNP Array data analysis for detection of PAR1 region deletions in order to confirm the absence of P2RY8-CRLF2 gene fusion not detected by RNA-Seq or FISH methods in our cohort. The SNP-Array method was based on the Infinium HD whole-genome genotyping assay with the HumanCytoSNP-12 BeadChip (Illumina Inc., San Diego, CA), which covers the entire genome with an average spacing of $9.6 \mathrm{~kb}$. This coverage allows an average resolution of $31 \mathrm{~kb}$ which was used for detection of PAR1 region deletion.

\section{Statistical analysis}

Differences in the prevalence of parameters between the groups were determined using the Mann-Whitney test or Independent-Samples T-test for continuous variables depending on their distributions. For categorical analyses, either a Chi-square or a Fisher exact test was used. Univariate and multivariate Cox proportional hazard regression models were used to evaluate the effect of noncanonical B-ALL genomic alterations on survival. The Kaplan-Meier method was used to estimate the time to event distributions (overall survival and event-free survival), the Log-Rank test was used to compare differences in survival curves. The overall survival (OS) was computed from the date of diagnosis until the date of death or last known follow-up date. The event-free survival (EFS) was defined as the time from diagnosis to the event of resistant disease, relapse, induction death, death in remission, second malignancy or date of the last follow-up if a patient had no events. A $p$-value $<0.05$ was considered to indicate statistical significance. Statistical analyses were performed using SPSS software version 20.

\section{Results \\ Study population}

Overall, one hundred and sixty 1-65year-old patients representing over $95 \%$ of the $B C R-A B L 1$ negative B-ALL patient population in Lithuania during the July 2008 December 2017 period were included into this study (Table 1). One hundred and twenty-two (76.3\%) patients were younger than 18 years of age. The majority of pediatric patients $(59.5 \%)$ were stratified to the NOPHO ALL-2008 standard risk treatment arm. In contrast, more than half of the adult patients were stratified either to the intermediate $(44.7 \%)$ or high risk/high risk SCT disease (29.0\%).

\section{Genomic analysis \\ Gene fusion analysis}

G-banding/SNP-Array, FISH and standard RT-PCR methods [25] were used to identify canonical B-ALL genomic alterations at diagnosis. In order to detect noncanonical B-ALL genomic lesions, we performed RNASeq and CRLF2 gene break FISH analyses in B-ALL 
Table 1 Clinical characteristics of B-ALL patients

\begin{tabular}{|c|c|c|c|c|}
\hline & $1-17$ yo & $18-65$ yo & All & $p$-Value \\
\hline \multicolumn{5}{|l|}{ Age groups } \\
\hline Number of patients & $122(76.3 \%)$ & $38(23.7 \%)$ & 160 (100\%) & \\
\hline Median age (range) & $4(1-17)$ & $32(18-65)$ & $5(1-65)$ & \\
\hline \multicolumn{5}{|l|}{ Sex: } \\
\hline Male & $69(56.6 \%)$ & $15(39.5 \%)$ & $84(52.5 \%)$ & 0.093 \\
\hline Female & $53(43.4 \%)$ & $23(60.5 \%)$ & $76(47.5 \%)$ & \\
\hline \multicolumn{5}{|l|}{ Risk group: } \\
\hline SR & $72(59.5 \%)$ & $7(18.4 \%)$ & 79 (49.7\%) & $<0.001$ \\
\hline IR & $38(31.4 \%)$ & $17(44.7 \%)$ & $55(34.6 \%)$ & \\
\hline HR & $5(4.1 \%)$ & $6(15.8 \%)$ & $11(6.9 \%)$ & \\
\hline HR-SCT & $3(2.5 \%)$ & $5(13.2 \%)$ & $8(5 \%)$ & \\
\hline Induction failure & $3(2.5 \%)$ & $3(7.9 \%)$ & $6(3.8 \%)$ & \\
\hline Not risk grouped & 1 & 0 & 1 & \\
\hline \multicolumn{5}{|l|}{ Induction: } \\
\hline Prednisolone & $113(92.6 \%)$ & $30(78.9 \%)$ & $143(89.4 \%)$ & 0.030 \\
\hline Dexamethasone & $9(7.4 \%)$ & $8(21.1 \%)$ & $17(10.6 \%)$ & \\
\hline \multicolumn{5}{|l|}{ WBC $\left(\times 10^{9} / \mathrm{I}\right):$} \\
\hline$<100$ & $113(92.6 \%)$ & $30(78.9 \%)$ & $143(89.4 \%)$ & 0.030 \\
\hline$\geq 100$ & $9(7.4 \%)$ & $8(21.1 \%)$ & $17(10.6 \%)$ & \\
\hline WBC median (range) & $14(1-641)$ & $10.5(0.9-481.9)$ & $13.5(0.9-641)$ & 0.672 \\
\hline $\mathrm{Hgb}(\mathrm{g} / \mathrm{l})$ median (range) & $83(24-140)$ & $90.5(52-142)$ & $84(24-142)$ & 0.117 \\
\hline Platelets median (range) & $62(0-457)$ & $37(5-320)$ & $54.5(0-457)$ & 0.075 \\
\hline \multicolumn{5}{|l|}{ CNS Status: } \\
\hline CNS1 & $104(85.2 \%)$ & 33 (86.8\%) & 137 (85.6\%) & 0.281 \\
\hline CNS2 & $14(11.5 \%)$ & $2(5.3 \%)$ & 16 (10\%) & \\
\hline CNS3 & $4(3.3 \%)$ & $3(7.9 \%)$ & 7 (4.4\%) & \\
\hline
\end{tabular}

$S R$ Standard risk, IR Intermediate risk, HR High risk, HR-SCT High risk-stem cell transplant groups, WBC White blood cells, HgB Hemoglobin, CNS central nervous system

cases lacking canonical gene fusions or $\operatorname{dic}(9: 20) /$ iAMP21 aberrations (Fig. 1).

In total, 99/160 (61.9\%) cases harbored at least one canonical B-ALL genomic alteration (Table 2, Fig. 1). High hyperdiploidy was identified in 35/160 (21.9\%) patients. Low hypodiploidy was present in $5 / 160$ (3.1\%) cases. ETV6-RUNX1 fusions were detected in 34/160 (21.3\%) cases and were more common among children than adults (33 children vs. 1 adult, $p=0.001$ ). In contrast, KMT2A gene rearrangements were detected in $11 / 160$ (6.9\%) B-ALL cases (4 children vs. 7 adults). Importantly, RNA-Seq analysis identified two additional $K M T 2 A$ gene rearrangements (del(11q23)/KMT2A-CBL, del(11q23)/ KMT2A-ATP5L) that had been missed by FISH. iAMP21 aberration was exclusive to the pediatric group $(n=3$, $1.9 \%)$ while $\operatorname{dic}(9 ; 20)$ was present in $1 / 160(0.6 \%)$ adult patient.

After the exclusion of two patients with KMT2A gene rearrangements identified by RNA-Seq, remaining cases without canonical B-ALL gene fusions and cases with high hyperdiploidy or low hypodiploidy $(n=101)$ were selected for RNA-Seq and CRLF2 gene break FISH analysis to identify other kinase and cytokine receptor activating lesions (Fig. 1).

In-frame fusions of ABL-class genes were detected in 3/101 (3\%) patients (Table 2; Fig. 1, Fig. 2). One case had $\mathrm{t}(9 ; 12) / E T V 6-A B L 1$ fusion previously reported in both lymphoid and myeloid leukemias [26]. The remaining two cases harbored $\mathrm{t}(1 ; 7) / Z C 3 H A V 1-A B L 2$ and $\mathrm{t}(5 ; 5) / E B F 1-P D G F R B$ fusions. All ABL-class fusions were exclusive to adults $(p=0.003)$.

JAK-STAT pathway fusions were identified in 4/101 (4\%) cases. ABL-class and JAK-STAT pathway fusions were mutually exclusive. RNA-Seq identified $t(9 ; 22) /$ $B C R-J A K 2$ fusion in one pediatric patient. FISH analysis revealed three cases with $\mathrm{t}(\mathrm{Y} ; 14)(\mathrm{X} ; 14) / I G H$ CRLF2 gene fusion, of which two were adults. BCR$J A K 2$ fusion was detected in one case with high 


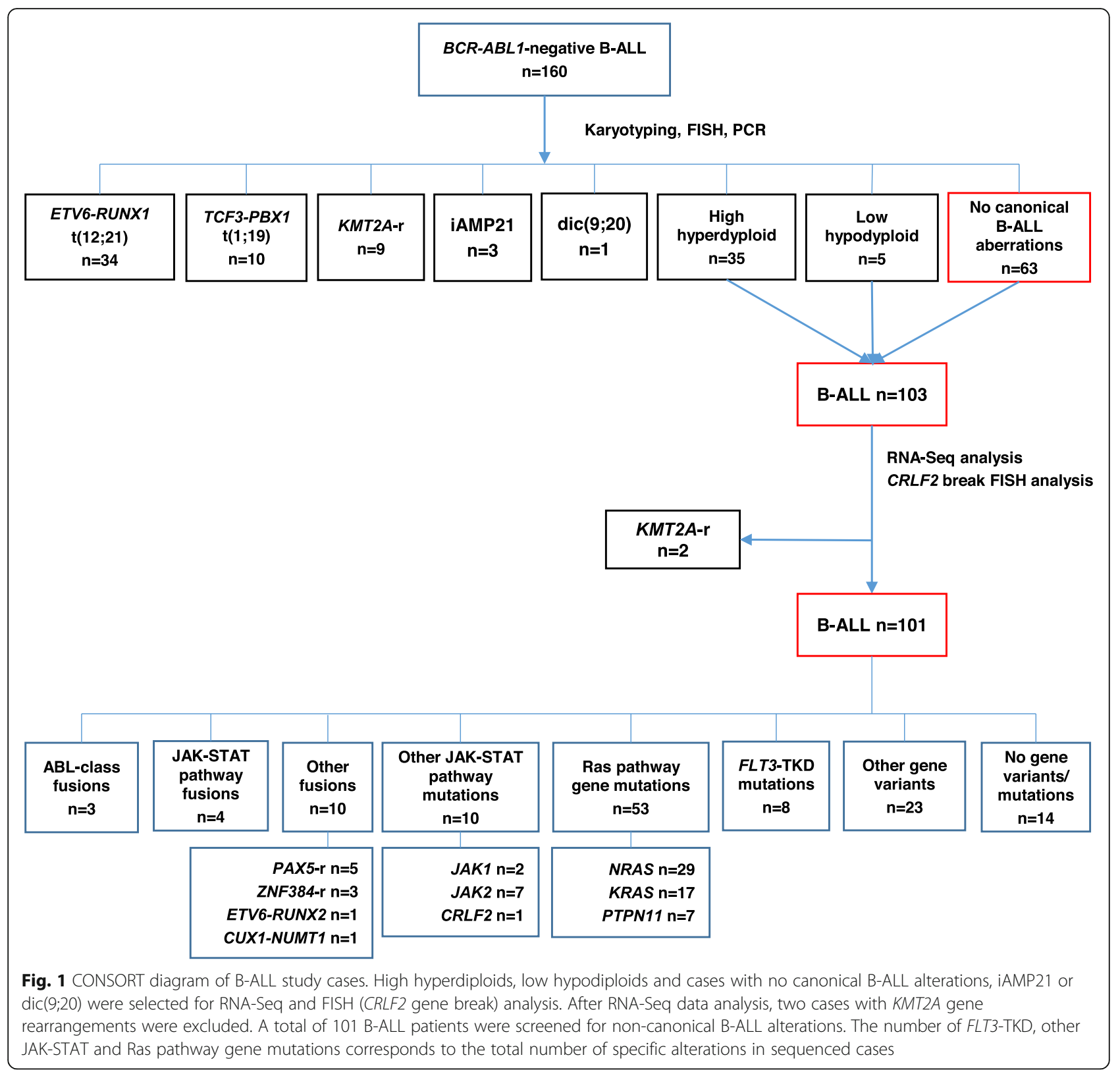

hyperdiploidy which further confirms that JAK-STAT pathway gene fusions can be detected in this entity. Both adult cases with IGH-CRLF2 fusions had additional gene mutations. One IGH-CRLF2-positive case harbored FLT3-TKD ${ }^{\mathrm{D} 835 \mathrm{Y}}$ and NRAS ${ }^{\mathrm{G} 13 \mathrm{R}}$ gene mutations while another case had $C R L F 2^{\mathrm{F2} 32 \mathrm{C}}$ gene mutation. RNA-seq and FISH analysis detected no P2RY8$C R L F 2$ fusions in our study patients. SNP Array analysis was available for $81 / 101$ (80.2\%) of the sequenced B-ALL patients. No deletions of PAR1 region were identified in any of the cases confirming the absence of P2RY8-CRLF2 fusion.

We identified other gene fusions in 10/101 (9.9\%) pediatric B-ALL cases. Five cases had PAX5 gene rearrangements: $\mathrm{t}(9 ; 18) / P A X 5-G R E B 1 L, \quad \mathrm{t}(9 ; 20) / P A X 5$ NCOA5, dic(9;12)/PAX5-ETV6, dic(3;9)/PAX5-FOXP1 and $\operatorname{dic}(9 ; 20) / P A X 5-N O L 4 L$. One case with PAX5GREB1L fusion had an additional $J A K 1^{\mathrm{F} 838 \mathrm{~V}}$ mutation, while in the other two $P A X 5$-rearranged cases $K R A S^{\mathrm{G} 12 \mathrm{~V}}$ and $N R A S^{\mathrm{G} 12 \mathrm{C}}$ mutations were identified. Three cases had fusions involving ZNF384 gene (EP300-ZNF384, $n=$ 2; TCF3-ZNF384, $n=1$ ) of which the TCF3-ZNF384 positive case had an additional $N R A S^{\mathrm{G} 13 \mathrm{R}}$ mutation. Though ETV6-RUNX1 is the most common alteration in childhood B-ALL, data analysis revealed a novel fusion of ETV6 and RUNX2 genes in one pediatric patient while another patient harbored a $t(7 ; 15) / C U X 1-N U M T 1$ fusion. 
Table 2 Genomic subgroups of canonical and non-canonical B-ALL alterations in study patients

\begin{tabular}{|c|c|c|c|c|c|}
\hline & Genomic alterations & $\begin{array}{l}\text { Pediatric group }(n= \\
122)\end{array}$ & $\begin{array}{l}\text { Adult group }(n= \\
38 \text { ) }\end{array}$ & $\begin{array}{l}\text { Total cohort }(n= \\
160)\end{array}$ & $\begin{array}{l}p \text {-Value (Chi- } \\
\text { Square) }\end{array}$ \\
\hline \multirow{8}{*}{$\begin{array}{l}\text { Canonical } \\
\text { alterations }\end{array}$} & $\mathrm{t}(12 ; 21) / E T V 6-R U N X 1$ & $33(27.1 \%)$ & $1(2.6 \%)$ & $34(21.3 \%)$ & $<0.001$ \\
\hline & $\mathrm{t}(1 ; 19) / T C F 3-P B X 1$ & $7(5.7 \%)$ & $3(7.9 \%)$ & $10(6.3 \%)$ & 0.701 \\
\hline & $\begin{array}{l}11 \mathrm{q} 23 / K M T 2 A \text { gene } \\
\text { rearrangements }\end{array}$ & $4(3.3 \%)$ & 7 (18.4\%) & $11(6.9 \%)$ & 0.004 \\
\hline & iAMP21 & $3(2.5 \%)$ & 0 & $3(1.9 \%)$ & 0.331 \\
\hline & $\operatorname{dic}(9 ; 20)$ & 0 & $1(2.6 \%)$ & $1(0.6 \%)$ & 0.071 \\
\hline & High hyperdiploidy & $32(26.2 \%)$ & $3(7.9 \%)$ & 35 (21.9\%) & 0.030 \\
\hline & Low hypodiploidy & $2(1.6 \%)$ & $3(7.9 \%)$ & $5(3.1 \%)$ & 0.086 \\
\hline & No canonical alterations & $41(33.6 \%)$ & $20(52.7 \%)$ & $61(38.1 \%)$ & \\
\hline \multirow{7}{*}{$\begin{array}{l}\text { Non-canonical } \\
\text { alterations }\end{array}$} & & $n=75$ & $n=26$ & $n=101$ & \\
\hline & ABL-class fusions & 0 & $3(11.5 \%)$ & $3(3 \%)$ & 0.003 \\
\hline & JAK-STAT pathway fusions & $2(2.7 \%)$ & $2(7.7 \%)$ & $4(4 \%)$ & 0.262 \\
\hline & Other fusions ${ }^{a}$ & $10(13.3 \%)$ & 0 & $10(9.9 \%)$ & 0.050 \\
\hline & JAK-STAT pathway mutations & $6(8 \%)$ & $4(15.4 \%)$ & $10(9.9 \%)$ & 0.182 \\
\hline & Ras pathway mutations & $39(52 \%)$ & $14(53.8 \%)$ & $53(52.5 \%)$ & 0.772 \\
\hline & FLT3-TKD mutations & $7(9.3 \%)$ & 1 (3.8\%) & 8 (7.9\%) & 0.378 \\
\hline
\end{tabular}

a PAX5-NCOA5, PAX5-ETV6, PAX5-FOXP1, PAX5-NOL4L, PAX5-GREB1L, EP300-ZNF384, TCF3-ZNF384, ETV6-RUNX2, CUX1-NUTM1

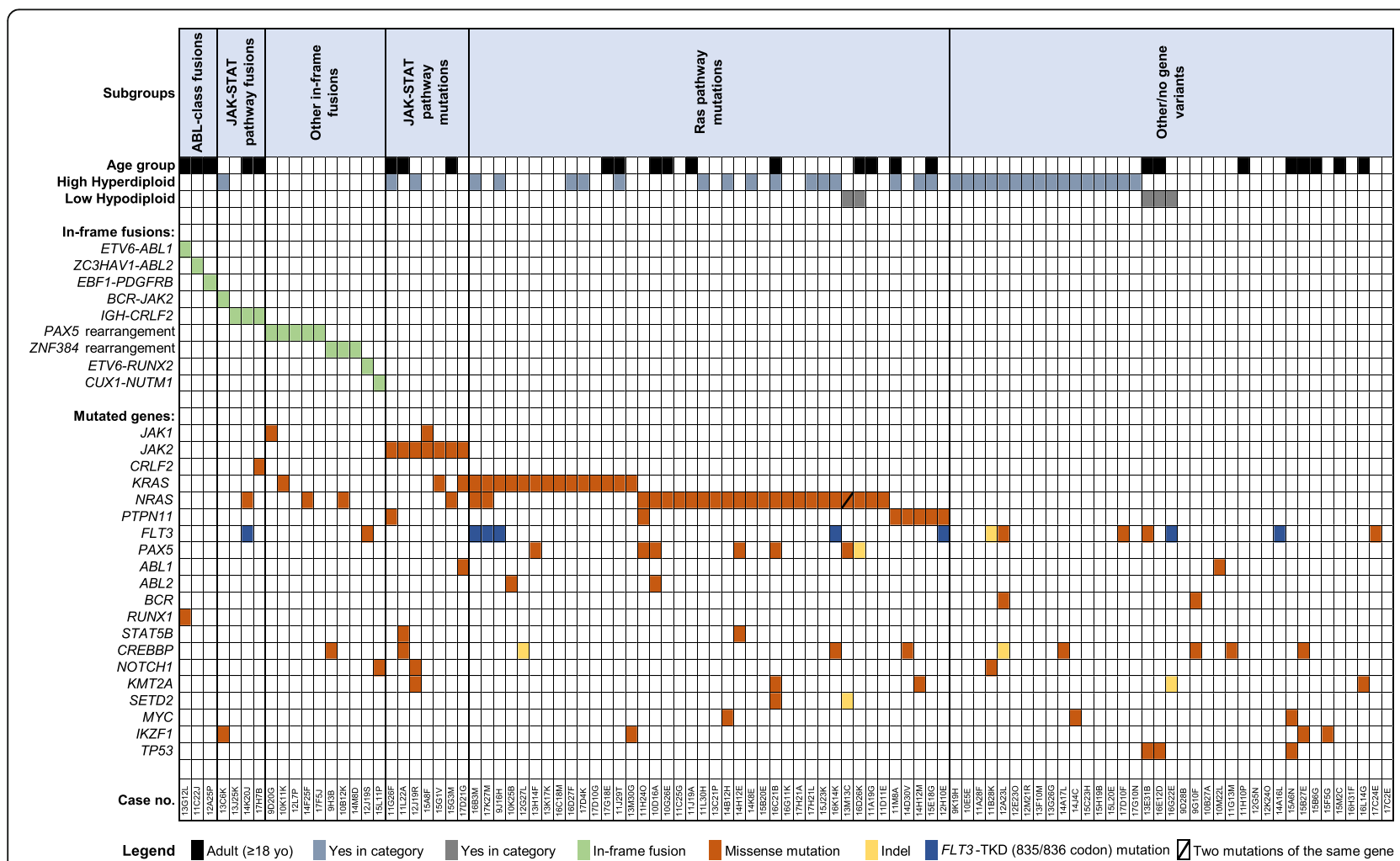

Fig. 2 Gene fusions and mutations identified by the RNA-Seq and FISH methods. The cohort is divided into patients with ABL-class fusions, JAKSTAT pathway fusions, other JAK-STAT-activating mutations, Ras pathway mutations, and cases with other or no gene variants 


\section{Gene mutation analysis}

Gene mutation analysis of RNA-Seq data revealed ten other JAK-STAT pathway mutations in a total of 9/101 (8.9\%) cases: JAK1 $(n=2), J A K 2(n=7)$, CRLF2 $(n=1)$ (Table 2; Fig. 2, Additional file: Table S2). One case had both $J A K 1$ and $J A K 2$ gene mutations in the same sample. In all cases, protein kinase 1 and kinase 2 domains of $J A K 1$ and $J A K 2$ genes were affected. Four $J A K 2$-mutated cases were co-mutated with Ras pathway genes (KRAS $\mathrm{n}=2 ;$ NRAS $\mathrm{n}=1 ;$ PTPN11 $\mathrm{n}=1$ ).

A total of fifty-three Ras pathway gene point mutations were detected in 48/101 (47.5\%) cases (Table 2; Fig. 2; Additional file 1: Table S2). NRAS gene mutations were the most common $(n=29)$ while the incidence of KRAS $(n=17)$ and PTPN11 $(n=7)$ gene mutations was lower. One case had mutations in NRAS and PTPN11 genes while another case had two different NRAS gene mutations (G12S and G12A) in the same sample. Two other cases had both KRAS and NRAS gene mutations in the same sample. Ras pathway mutations were detected in 16/35 (45.7\%) high hyperdyploid and 2/5 (40\%) low hypodiploidy cases.

FLT3-TKD activating mutations of codons D835 ( $n=$ 5) and I836 $(n=3)$ were found in $8 / 101$ (7.9\%) cases. Most of the FLT3-TKD positive cases (75\%) were present with Ras pathway gene mutations. Other FLT3 gene kinase domain point mutations were present in 5/ 101 (5\%) patients (Fig. 2).

Other gene mutations were identified in $23 / 101$ $(22.8 \%)$ patients. Mutations in FLT3 $(n=7)$, CREBBP $(n=5)$ and TP53 $(n=3)$ genes were the most recurrent in this group of patients. RNA-Seq and FISH methods failed to identify ALL-related gene fusions and mutations in $14 / 101(13.9 \%)$ cases.

\section{Clinical outcome of patients with ABL-class or JAK-STAT fusions}

Five of $26(19.2 \%)$ adult and two of 75 (2.7\%) pediatric B-ALL cases without canonical B-ALL alterations (5/38 (13.2\%) adult and 2/122 (1.6\%) pediatric BCR-ABL1negative B-ALL cases) were positive for either ABL-class or JAK-STAT pathway fusions (AJS-positive group) (Table 3). Overall, both EFS and OS were worse in the AJS-positive group vs the AJS-negative $(n=153)$ (Fig. 3a).

We further compared the outcome of AJS positive $(n=5)$ vs. AJS negative $(n=33)$ B-ALL cases in adults since the number of AJS-positive pediatric cases was too small for detailed analysis. Four AJS-positive adult patients were evaluated for residual disease on induction day 15 (one patient died during induction). All four AJSpositive patients $(100 \%)$ had $\geq 5 \%$ blasts on day 15 compared to $9(29 \%)$ AJS-negative patients $(p=0.019)$ (Table 4). After day 15, one patient was assigned to block treatment; therefore, three patients had MRD data available on day 29. MRD levels on days 29 and 79 were higher in the AJS-positive group compared to the AJSnegative group. As a result of a poor MRD response, more AJS-positive than AJS-negative adult patients had induction failure or were assigned to HR/HR-SCT group (4 (80.0\%) vs 10 (30.3\%), respectively, $p=0.052$ ).

The median observation time in adults was 39 months. The 75th percentile EFS was 5 vs. 35 months $(p=0.009)$ and OS was 14 vs. 36 months $(p=0.098)$ in AJS-positive vs. AJS-negative adults, respectively (Fig. $3 \mathrm{~b}$ ). Since all patients were assigned to different risk groups according to their canonical B-ALL alterations and MRD response, we performed a multivariate analysis of risk-group assignment and AJS-positivity on the outcome in adults. In multivariate analysis, having ABL-class or JAK-STAT pathway fusions was an independent risk factor for worse $\operatorname{EFS}(p=0.046)$ (Table 5).

\section{Discussion}

We present the first Baltic European population-based study of genomic alterations among pediatric and adult $B C R-A B L 1$-negative B-ALL patients. All patients were uniformly treated according to the NOPHO ALL-2008 protocol with risk stratification according to both the canonical B-ALL genomic lesions and minimal residual disease. We selected targeted RNA-Seq and FISH methods for the detection of known and novel gene rearrangements of ABL-class, JAK-STAT pathway genes and other kinase alterations.

In our study, ABL-class fusions were identified in 3/ 101 (3\%) B-ALL cases without canonical B-ALL alterations or 3/160 (1.9\%) BCR-ABL1-negative B-ALL cases. All positive cases were adults (3/38, 7.9\%) (Fig. 2). In comparison, in the Dutch/German cohort 9 of 153 (5.9\%) pediatric B-ALL patients without canonical BALL alterations harbored ABL-class fusions [14]. Another European study by Zaliova et al. revealed only 1/ 75 (1.3\%) pediatric B-ALL case with $A B L 1$ gene rearrangement [27] while ABL-class fusions were present in 40/1389 (2.9\%) high-risk pediatric B-ALL patients in an US Children's Oncology Group study [13]. Heatley at el. performed targeted RNA-Seq in 63 adolescent/young adults (16-39 yo) and 63 adults (40-88 yo) with $B C R$ ALB1-negative B-ALL [28]. ABL-class fusions were found in 4/126 (3.2\%) of these B-ALL cases. A study by Garrido et al. used the FISH method to analyze 39 adult B-ALL patients negative for the BCR-ABL1 and KMT2A gene rearrangements and identified $3 / 39$ (7.7\%) cases with ABL-class fusions ( $A B L 1 n=2 ; \operatorname{CSF1R} n=1)$ [29]. In a similar study from a UKALL14 clinical trial, ABLclass abnormalities were present in $6 / 648(<1 \%)$ of BALL patients [30]. The incidence of ABL-class fusions of $7.9 \%$ in our adult patient cohort was largely in line with 
Table 3 Genetic features and clinical outcome of ABL-class or JAK-STAT pathway fusion (AJS)-positive patients

\begin{tabular}{|c|c|c|c|c|c|c|c|c|c|c|c|}
\hline $\begin{array}{l}\text { Case } \\
\text { no. }\end{array}$ & $\begin{array}{l}\text { Age } \\
\text { group }\end{array}$ & $\begin{array}{l}\text { In-frame gene } \\
\text { fusion }\end{array}$ & WBC & $\begin{array}{l}\text { DEX / } \\
\text { PREDNI }\end{array}$ & $\begin{array}{l}\text { MRD } \\
\text { D15 }\end{array}$ & MRD D29 & MRD D79 & $\begin{array}{l}\text { Risk } \\
\text { Group }\end{array}$ & $\begin{array}{l}\text { alloSCT } \\
(\mathrm{Y} / \mathrm{N})\end{array}$ & $\begin{array}{l}\text { Event } \\
(\mathrm{Y} / \mathrm{N})\end{array}$ & Comment \\
\hline $\begin{array}{l}\text { Case } \\
1\end{array}$ & Adult & ETV6-ABL1 & 270 & DEX & - & - & - & - & $\mathrm{N}$ & Y & Induction death \\
\hline $\begin{array}{l}\text { Case } \\
2\end{array}$ & Adult & ZC3HAV1-ABL2 & 72 & PREDNI & $30.5 \%$ & $6.5 \%$ & $0.01 \%$ & $\mathbb{I R}$ & Y & Y & $\begin{array}{l}\text { Death of sepsis after } \\
\text { alloSCT in CR1 }\end{array}$ \\
\hline $\begin{array}{l}\text { Case } \\
3\end{array}$ & Adult & EBF1-PDGFRB & 258 & DEX & $45.3 \%$ & $\begin{array}{l}0.93 \% \\
\text { (POST A1) }\end{array}$ & $\begin{array}{l}0.7 \% \\
\text { (POST B1) }\end{array}$ & HR-SCT & Y & Y & $\begin{array}{l}\text { Relapse after alloSCT and } \\
\text { death }\end{array}$ \\
\hline $\begin{array}{l}\text { Case } \\
4\end{array}$ & Adult & IGH-CRLF2 & 4 & PREDNI & $11.6 \%$ & $20.3 \%$ & $3.4 \%$ & HR-SCT & Y & Y & $\begin{array}{l}\text { Relapse after alloSCT and } \\
\text { alive in CR2 }\end{array}$ \\
\hline $\begin{array}{l}\text { Case } \\
5\end{array}$ & Adult & IGH-CRLF2 & 104 & DEX & $44.3 \%$ & $8 \%$ & $1.65 \%$ & HR-SCT & Y & N & Alive after alloSCT in CR1 \\
\hline $\begin{array}{l}\text { Case } \\
6\end{array}$ & Pediatric & IGH-CRLF2 & 35 & PREDNI & $0.22 \%$ & $<0.1 \%$ & $0.3 \%$ & HR-SCT & Y & $\mathrm{N}$ & Alive after alloSCT in CR1 \\
\hline $\begin{array}{l}\text { Case } \\
7\end{array}$ & Pediatric & $B C R-J A K 2$ & 5 & PREDNI & $1.8 \%$ & $0.33 \%$ & $<0.1 \%$ & $\mathbb{R}$ & $\mathrm{N}$ & N & Alive in CR1 \\
\hline
\end{tabular}

WBC White blood cells, DEX Dexamethasone, PREDNI Prednisolone, D15 Day 15, D29 Day 29, D79 Day 79, MRD Minimal residual disease, alloSCT Allogenic stem cell transplant, $C R 1$ First clinical remission, $C R 2$ Second clinical remission
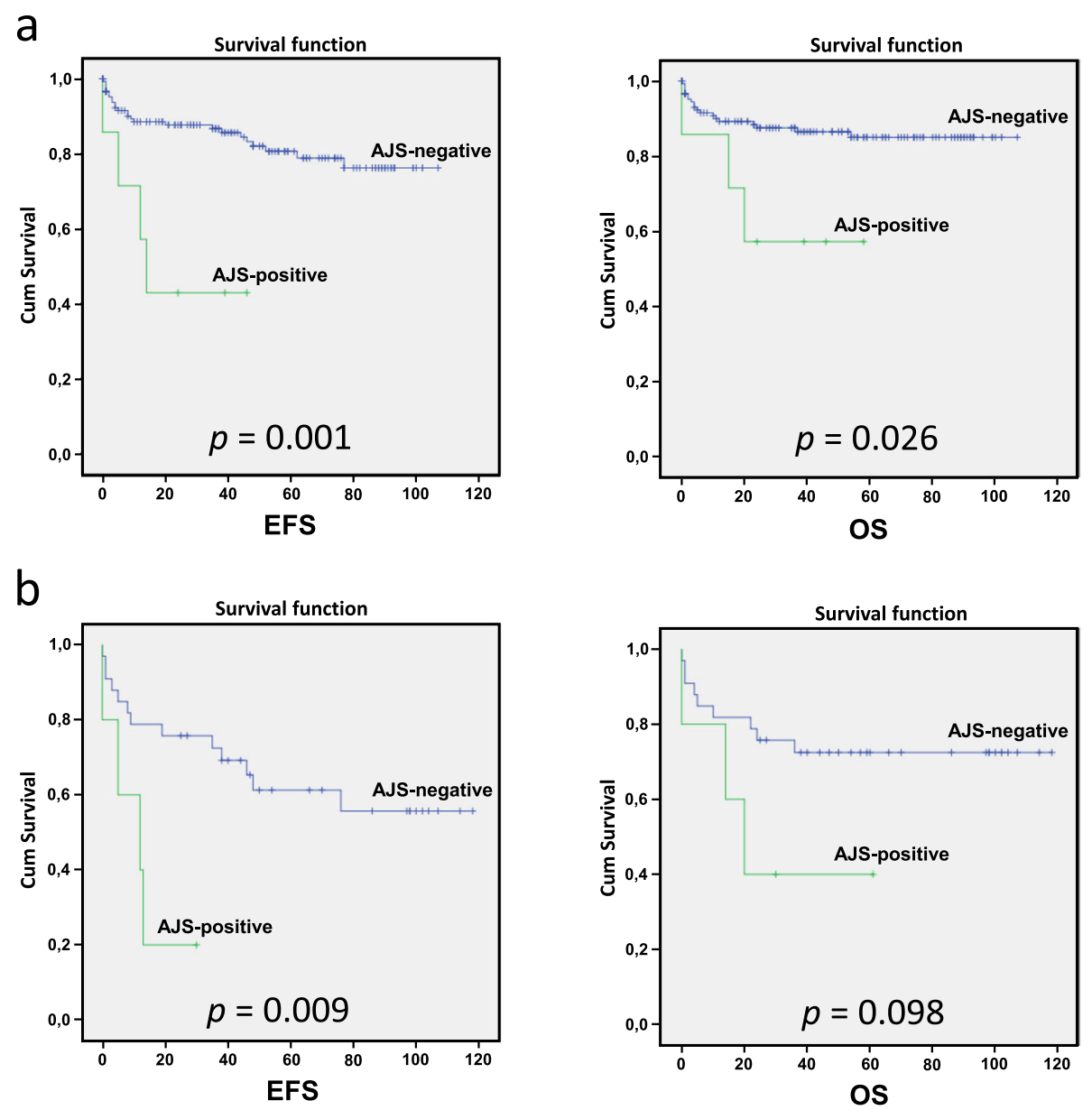

Fig. 3 Event-free survival (EFS) and overall survival (OS) in months in ABL-class or JAK-STAT pathway fusion (AJS)-positive vs. AJS-negative patients. a, all B-ALL patients (7 AJS-positive vs 153 AJS-negative pts); b, adult B-ALL patients (5 AJS-positive vs 33 AJS-negative pts) 
Table 4 Minimal residual disease (MRD) of AJS-positive vs. AJS-negative adult patients on days 15, 29 and 79

\begin{tabular}{llllc}
\hline Timepoint & MRD & AJS-positive $(\boldsymbol{n}=\mathbf{5})$ & AJS-negative $(\boldsymbol{n}=\mathbf{3 3})$ & $\boldsymbol{p}$-Value (Chi-Square) \\
\hline D15 & $<5 \%$ & $0(0 \%)$ & $22(71 \%)$ & 0.019 \\
& $\geq 5 \%$ & $4(100 \%) 1$ missing & $9(29 \%) 2$ missing & $<0.001$ \\
D29 & $<5 \%$ & $0(0 \%)$ & $30(96.8 \%)$ & $1(3.2 \%) 2$ missing \\
D29 & $\geq 5 \%$ & $3(100 \%) 2$ missing & $21(67.7 \%)$ & 0.011 \\
& $<0.1 \%$ & $0(0 \%)$ & $10(32.3 \%) 2$ missing & 0.120 \\
D79 & $\geq 0.1 \%$ & $3(100 \%) 2$ missing & $26(89.7 \%)$ & $3(10.3 \%) 4$ missing \\
& $<0.1 \%$ & $2(50 \%)$ & $2(50 \%) 1$ missing &
\end{tabular}

AJS ABL-class or JAK-STAT pathway fusions, D15 Day 15, D29 Day 29, D79 Day 79m, MRD Minimal residual disease

published adult studies. Conversely, we did not detect ABL-class fusions in our pediatric B-ALL patients.

We identified JAK-STAT pathway fusions in 4/101 (4\%) cases without canonical B-ALL alterations. JAKSTAT pathway fusions occur in approximately $3-5 \%$ of childhood and in up to $15 \%$ of adult B-ALL [3]. A study by Heatley et al. showed the incidence rate in adults of $15.9 \%$ [28]; however, another study revealed that only $5.1 \%$ of adult B-ALL had JAK-STAT pathway fusions [30]. Similarly, our data indicate a lower frequency of JAK-STAT pathway fusions in both adult and pediatric Lithuanian B-ALL patients.

Overall, the frequency of CRLF2 rearrangements in BALL is approximately $5 \%$ and the rate gets higher in cases without canonical B-ALL alterations (10-30\%) and in patients with Down syndrome $(>50 \%)[16,27,28,31$, 32]. In our study, IGH-CRLF2 fusions were identified in 3/101 (2.9\%) B-ALL cases without canonical B-ALL alterations or in $3 / 160$ (1.9\%) BCR-ABL1-negative B-ALL cases. Notably, we did not detect any P2RY8-CRLF2 gene fusions in our cohort by either RNA-Seq or CRLF2 gene break FISH. In comparison, a Swedish study identified CRLF2 gene rearrangements in 16 of 189 (8.5\%) pediatric $B C R-A B L$-negative B-ALL patients, of which P2RY8-CRLF2 fusion was the most common $(12 / 16$, 75\%) [16]. P2RY8-CRLF2 gene fusion is the result of deletion of PAR1 region in either $\mathrm{X}$ or $\mathrm{Y}$ chromosomes. To further confirm the absence of P2RY8-CRLF2 fusion, we used SNP Array data of 81/101 (80.2\%) sequenced patients and did not detect any deletions in the corresponding PAR1 region. In addition, another study has shown that P2RY8-CRLF2 fusion can be identified using the RNA-Seq method and an analysis algorithm similar to ours [33], making it unlikely that P2RY8$C R L F 2$ fusion was missed due to technical reasons in our study patients. CRLF2 gene rearrangements are common in populations with Hispanic ancestry and are associated with increased risk of relapse in both children and adults [17, 34-36]. Population differences may explain a lower frequency of $I G H-C R L F 2$ and the absence of P2RY8-CRLF2 gene fusions in our cohort. In other BALL studies, approximately half of CRLF2-rearranged patients also harbored additional JAK1 or JAK2 gene mutations [13], however our positive cases had no such mutations. Of note, one case had FLT3-TKD ${ }^{\mathrm{D} 835 \mathrm{Y}}$ and $N R A S^{\mathrm{G} 13 \mathrm{R}}$ gene mutations and another case was positive for a $C R L F 2^{\mathrm{F} 232 \mathrm{C}}$ activating mutation. $C R L F 2^{\mathrm{F} 232 \mathrm{C}}$ gene mutation is known to promote constitutive dimerization and cytokine-independent growth which results in gene overexpression in a similar manner as with CRLF2 gene rearrangement [37].

Other gene fusions were found in 10/101 (9.9\%) patients and were exclusive to the pediatric group (Fig. 2). RNA-Seq data were used for gene mutation analysis with a caveat that only expressed sequence variants of targeted genes which could be evaluated. In most cases, the coverage of particular mutations calculated from RNASeq data was inadequate to accurately determine their frequencies in the sample. Therefore, we did not evaluate mutation-based clonality/subclonality. In our study,

Table 5 Multivariate analysis of EFS and OS of MRD-assigned risk and AJS-positive groups in adults

\begin{tabular}{lllll}
\hline Risk Groups & EFS & & OS \\
\cline { 2 - 3 } & Hazard Ratio & $\boldsymbol{p}$-Values & Hazard Ratio & $\boldsymbol{p}$-Values \\
\hline SR & reference & - & reference & - \\
IR & $0.885(0.220-3.570)$ & 0.846 & $2.219(0.257-19.136)$ & 0.468 \\
HR+ HR-SCT & $0.753(0.146-3.875)$ & 0.734 & $1.568(0.134-18.298)$ & 0.720 \\
AJS-positive & $5.545(1.057-29.090)$ & 0.046 & $2.783(0.436-17.881)$ & 0.278 \\
\hline
\end{tabular}

$S R$ Standard risk, IR Intermediate risk, HR High risk, HR-SCT High risk-stem cell transplant groups, AJS ABL-class or JAK-STAT pathway fusions, EFS Event-free survival, OS Overall survival, MRD Minimal residual disease 
other gene fusions and point mutations in FLT3, JAKSTAT and Ras pathway genes had no prognostic significance on either EFS or OS among all age groups.

RNA-Seq analysis revealed two adult B-ALL cases with $K M T 2 A$ gene rearrangements that had been missed by FISH analysis at diagnosis. Both samples had blast counts of $>90 \%$. We re-ran the FISH analysis; however, the secondary results were also negative. Notably, both fusions were formed as a result of the aberrations of the $11 \mathrm{q} 23$ chromosome region. The close proximity of fused genes and relatively small size of chromosome aberrations could have potentially caused false negative FISH results. Patients with $K M T 2 A$ gene rearrangements have lower survival rates and generally require therapy intensification in first remission [2]. KMT2A-ATP5L fusion was also recently described as an unfavorable prognostic marker in young adults with Ph-like ALL [38]. Our findings demonstrate the additional advantage of RNA-Seq diagnostic method in B-ALL patients who are negative for canonical B-ALL fusions by FISH analysis.

Ph-like B-ALL has been associated with a worse outcome in several studies $[18,19,39]$. Roberts with colleagues [21] performed a gene expression profiling of 344 B-ALL patients and found that 40/344 (11.6\%) children with Ph-like B-ALL had higher MRD values on both day 19 and at the end of induction compared to non-Ph-like B-ALL patients. However, the EFS and OS were not different in both groups due to MRD-risk directed treatment of the Total Therapy XV protocol [21]. Ph-like B-ALL adult patients were noted to have a lower probability of achieving molecular complete remission, and had a lower probability of continuous complete remission and OS in the GMALL studies 06/99 and 07/03 [20]. Only limited MRD-directed treatment was applied in GMALL 07/03 study with persistently MRD positive standard-risk patients having an option of SCT [40]. In another study of patients entering different study protocols, Ph-like B-ALL was associated with a worse outcome in young but not older adults [41]. Likewise, lower EFS and OS were noted in adult Ph-like B-ALL patients in the MD Anderson studies [19]. In a CALGB10403 study of young (18-40 year-old) adults treated according to a pediatric high-risk non-MRD directed protocol, patients with Ph-like fusions had a 3 -year EFS of $42 \%$ in contrast to $69 \%$ for those without these fusions and patients with the Ph-like B-ALL signature were less likely to have the negative MRD compared to patients without this signature [42].

There are several important differences in our study. First, all patients were treated according to the MRDrisk directed NOPHO ALL-2008 protocol and patients with a poor MRD response were assigned to therapy intensification with or without allogeneic SCT [2]. Second, we studied the ABL-class or JAK-STAT pathway fusion- positive patients only who mostly, but not exclusively, clustered within a Ph-like group [18]. Nevertheless, we found that patients with ABL-class or JAK-STAT pathway fusions (AJS-positive group) were more likely to have a poor MRD response compared to patients without these fusions (AJS-negative group) and thus were more likely to be assigned to higher risk groups resulting in therapy intensification. In our study, AJS-positive adult patients had a lower EFS and a trend for lower OS. In multivariate analysis, AJS-positivity was a risk factor for worse $\operatorname{EFS}(p=0.046)$ but not OS $(p=0.278)$ in adults (Table 5).

Our results are supported by pediatric B-ALL studies focusing on a cytogenetic analysis of ABL-class and/or JAK-STAT pathway fusions. A study of UKALL2003 trial patients by O'Connor et al. [11] examined pediatric ALL patients with induction failure (leukemic blasts > $5 \%$ and/or MRD $\geq 5 \%$ ) revealing a high rate of ABL-class (>30\%) or CRLF2 (11\%) rearrangements. Similarly, in a study by Cario et al., 46 pediatric B-ALL patients with ABL-class fusions treated according to AIEOP-BFM protocols showed high rates of MRD ( $\geq 5 \times 10-4)$ positivity (71.4 and $51.2 \%$ after induction and consolidation, respectively) [43]. We observed similar poor MRD responses in our ABL-class / JAK-STAT fusion-positive adult patients despite MRD directed treatment. Importantly, ABL-class positive patients who received a TKI as part of their UKALL2011 protocol first remission treatment showed a lower relapse rate [12].

Our study has limitations. Though the NOPHO 2008 protocol included children and adults from Nordic, Baltic (Lithuania and Estonia) countries and Iceland, we had access to and studied Lithuanian patients only. The number of ABL-class or JAK-STAT pathway fusionpositive patients was low and a few events occurring by chance could have significantly affected the statistics of clinical outcome. As already mentioned, our results are not directly comparable to the previous studies of $\mathrm{Ph}$ like B-ALL. Nevertheless, the results of our study are clinically relevant. We report the results of a relatively large and homogenous group of pediatric and adult patients coming from the Baltic part of Europe and show that the incidence of ABL-class or JAK-STAT pathway fusions in this geographic area is lower as compared to the US or other European regions $[11-14,16,18,30]$. Our results suggest that AJS-positive group patients have a poor MRD response and MRD-risk directed treatment may not be sufficient to overcome the adverse effect of AJS-positivity in adults. Importantly, clinical studies have shown that specific ABL-class fusions can be successfully targeted with tyrosine kinase inhibitors such as dasatinib or imatinib even in refractory B-ALL [7, 8, 10, 12, 43]. Arguably, the detection of ABL-class or JAK-STAT pathway fusions could be reserved for poor B-ALL MRD 
responders. This could have significant financial and logistical implications since only a limited number of BALL patients will need to be tested for ABL-class or JAK-STAT pathway fusions.

\section{Conclusions}

ABL-class and JAK-STAT pathway fusions are uncommon in the population-based cohort of Lithuanian $B C R$ ABL1-negative B-ALL patients. Specifically, P2RY8$C R L F 2$ gene fusion was not detected using three different genome interrogation methods. The poor MRD response and an inferior clinical outcome in patients harboring either ABL-class or JAK-STAT pathway fusions should be confirmed in future prospective studies.

\section{Supplementary Information}

The online version contains supplementary material available at https://doi. org/10.1186/s12885-020-07781-6.

\section{Additional file 1: Table S1, Table S2.}

\section{Abbreviations}

ALL: Acute lymphoblastic leukemia; EFS: Event-free survival; FISH: Fluorescence in situ hybridization; GMALL: German multicenter study group for adult ALL; HR: High risk; IR: Intermediate risk; JAK-STAT: Janus kinase-signal transducers and activators of transcription; MRD: Minimal residual disease; NOPHO: Nordic Society for Pediatric Hematology and Oncology; OS: Overall survival; PCR: Polymerase chain reaction; SCT: Stem cell transplant; SNP: Single nucleotide polymorphism; SR: Standard risk; TKl: Tyrosine kinase inhibitor

\section{Acknowledgements}

The authors would like to thank the patients and their families for contributing to this study.

\begin{abstract}
Authors' contributions
RN performed the experiments and carried out bioinformatic analysis; VD performed the experiments; OM carried out statistical analysis; RS and GV were involved in collecting patient data; VD, OM, RS, EG, MS, JR were involved in manuscript editing. RN, LG were major contributors to study design and manuscript writing; LG supervised the project. All authors have read and approved the manuscript.
\end{abstract}

\section{Funding}

Not applicable.

\section{Availability of data and materials}

The datasets used during the current study are available from the corresponding author on reasonable request.

\section{Ethics approval and consent to participate}

The study was conducted in accordance with the Declaration of Helsinki, and the protocol was approved by Vilnius Regional Bioethics Committee. The patients provided written informed consent. The waiver for obtaining written informed consent from patients who could not be reached despite best efforts had been approved by Vilnius Regional Bioethics Committee according to national regulations.

\section{Consent for publication}

Not applicable.

\section{Competing interests}

The authors declare that they have no competing interests.

\section{Author details}

${ }^{1}$ Hematology, Oncology and Transfusion Medicine Center, Vilnius University Hospital Santaros Klinikos, Vilnius, Lithuania. ²Department of Experimental, Preventive and Clinical Medicine, State Research Institute Centre for Innovative Medicine, Vilnius, Lithuania. ${ }^{3}$ Institute of Clinical Medicine, Vilnius University, Vilnius, Lithuania. ${ }^{4}$ Center for Pediatric Oncology and Hematology, Vilnius University Hospital Santaros Klinikos, Vilnius, Lithuania.

Received: 6 September 2020 Accepted: 30 December 2020

Published online: 29 March 2021

\section{References}

1. Mullighan CG. The molecular genetic makeup of acute lymphoblastic leukemia. Hematol Am Soc Hematol Educ Program. 2012;2012:389-96.

2. Toft N, Birgens H, Abrahamsson J, Griškevičius L, Hallböök H, Heyman M, et al. Results of NOPHO ALL2008 treatment for patients aged 1-45 years with acute lymphoblastic leukemia. Leukemia. 2018;32(3):606-15.

3. Moorman AV. New and emerging prognostic and predictive genetic biomarkers in B-cell precursor acute lymphoblastic leukemia. Haematologica. 2016;101(4):407-16.

4. Den Boer ML, van Slegtenhorst M, De Menezes RX, Cheok MH, BuijsGladdines JG, Peters ST, et al. A subtype of childhood acute lymphoblastic leukaemia with poor treatment outcome: a genome-wide classification study. Lancet Oncol. 2009;10(2):125-34.

5. Mullighan CG, Su X, Zhang J, Radtke I, Phillips LA, Miller CB, et al. Deletion of IKZF1 and prognosis in acute lymphoblastic leukemia. N Engl J Med. 2009;360(5):470-80.

6. Roberts KG, Morin RD, Zhang J, Hirst M, Zhao Y, Su X, et al. Genetic alterations activating kinase and cytokine receptor signaling in high-risk acute lymphoblastic leukemia. Cancer Cell. 2012;22(2):153-66.

7. Weston BW, Hayden MA, Roberts KG, Bowyer S, Hsu J, Fedoriw G, et al. Tyrosine kinase inhibitor therapy induces remission in a patient with refractory EBF1-PDGFRB-positive acute lymphoblastic leukemia. J Clin Oncol. 2013;31(25):e413-6.

8. Roberts KG, Yang YL, Payne-Turner D, Lin W, Files JK, Dickerson K, et al. Oncogenic role and therapeutic targeting of ABL-class and JAK-STAT activating kinase alterations in Ph-like ALL. Blood Adv. 2017;1 (20):1657-71.

9. Ding YY, Stern JW, Jubelirer TF, Wertheim GB, Lin F, Chang F, et al. Clinical efficacy of ruxolitinib and chemotherapy in a child with Philadelphia chromosome-like acute lymphoblastic leukemia with GOLGA5-JAK2 fusion and induction failure. Haematologica. 2018;103(9):e427-31.

10. Lengline E, Beldjord K, Dombret H, Soulier J, Boissel N, Clappier E. Successful tyrosine kinase inhibitor therapy in a refractory B-cell precursor acute lymphoblastic leukemia with EBF1-PDGFRB fusion. Haematologica. 2013; 98(11):e146-8.

11. O'Connor D, Moorman AV, Wade R, Hancock J, Tan RM, Bartram J, et al. Use of minimal residual disease assessment to redefine induction failure in pediatric acute lymphoblastic leukemia. J Clin Oncol. 2017;35(6):660-7.

12. Moorman A, Schwab C, Kirkwood A, Winterman E, Hancock J, Kearns P, et al. Improved outcome for patients with acute lymphoblastic leukemia (ALL) and an ABL-class fusion following treatment with a tyrosine kinase inhibitor: preliminary data from UKALL2011. EHA Library. 2020;1:294937.

13. Reshmi SC, Harvey RC, Roberts KG, Stonerock E, Smith A, Jenkins H, et al. Targetable kinase gene fusions in high-risk B-ALL: a study from the Children's oncology group. Blood. 2017;129(25):3352-61.

14. Boer JM, Steeghs EM, Marchante JR, Boeree A, Beaudoin JJ, Beverloo HB, et al. Tyrosine kinase fusion genes in pediatric BCR-ABL1-like acute lymphoblastic leukemia. Oncotarget. 2017;8(3):4618-28.

15. Kotb A, El Fakih R, Hanbali A, Hawsawi Y, Alfraih F, Hashmi S, et al. Philadelphia-like acute lymphoblastic leukemia: diagnostic dilemma and management perspectives. Exp Hematol. 2018;67:1-9.

16. Lilljebjörn H, Henningsson R, Hyrenius-Wittsten A, Olsson L, Orsmark-Pietras C, von Palffy S, et al. Identification of ETV6-RUNX1-like and DUX4-rearranged subtypes in paediatric B-cell precursor acute lymphoblastic leukaemia. Nat Commun. 2016;7:11790.

17. Chiaretti S, Brugnoletti F, Messina M, Paoloni F, Fedullo AL, Piciocchi A, et al. CRLF2 overexpression identifies an unfavourable subgroup of adult B-cell precursor acute lymphoblastic leukemia lacking recurrent genetic abnormalities. Leuk Res. 2016;41:36-42. 
18. Roberts KG, Li Y, Payne-Turner D, Harvey RC, Yang YL, Pei D, et al. Targetable kinase-activating lesions in Ph-like acute lymphoblastic leukemia. N Engl J Med. 2014;371(11):1005-15.

19. Jain N, Roberts KG, Jabbour E, Patel K, Eterovic AK, Chen K, et al. Ph-like acute lymphoblastic leukemia: a high-risk subtype in adults. Blood. 2017; 129(5):572-81.

20. Herold T, Schneider S, Metzeler KH, Neumann M, Hartmann L, Roberts KG, et al. Adults with Philadelphia chromosome-like acute lymphoblastic leukemia frequently have IGH-CRLF2 and JAK2 mutations, persistence of minimal residual disease and poor prognosis. Haematologica. 2017;102(1): 130-8.

21. Roberts KG, Pei D, Campana D, Payne-Turner D, Li Y, Cheng C, et al. Outcomes of children with BCR-ABL1-like acute lymphoblastic leukemia treated with risk-directed therapy based on the levels of minimal residual disease. J Clin Oncol. 2014;32(27):3012-20.

22. Pui CH, Pei D, Raimondi SC, Coustan-Smith E, Jeha S, Cheng C, et al. Clinical impact of minimal residual disease in children with different subtypes of acute lymphoblastic leukemia treated with response-adapted therapy. Leukemia. 2017:31(2):333-9.

23. Holmfeldt L, Wei L, Diaz-Flores E, Walsh M, Zhang J, Ding L, et al. The genomic landscape of Hypodiploid acute lymphoblastic leukemia. Nat Genet. 2013;45(3):242-52.

24. Paulsson K, Lilljebjörn H, Biloglav A, Olsson L, Rissler M, Castor A, et al. The genomic landscape of high hyperdiploid childhood acute lymphoblastic leukemia. Nat Genet. 2015;47(6):672-6.

25. van Dongen J, Macintyre E, Gabert J, Delabesse E, Rossi V, Saglio G, et al. Standardized RT-PCR analysis of fusion gene transcripts from chromosome aberrations in acute leukemia for detection of minimal residual disease. Leukemia. 1999;13:1901-28.

26. Zaliova M, Moorman AV, Cazzaniga G, Stanulla M, Harvey RC, Roberts KG, et al. Characterization of leukemias with ETV6-ABL1 fusion. Haematologica. 2016;101(9):1082-93

27. Zaliova M, Stuchly J, Winkowska L, Musilova A, Fiser K, Slamova M, et al. Genomic landscape of pediatric B-other acute lymphoblastic leukemia in a consecutive European cohort. Haematologica. 2019;104(7):1396-406.

28. Heatley SL, Mayne B, McClure BJ, Kok C, Sadras T, Dang P, et al. Exploring the genomic diversity of AYA and adult high-risk B-ALL cases by mRNA sequencing. EHA learning center; 2018.

29. Garrido T, Soares MJ, Barbosa A, Amorim ML, Gomes P, Trigo F, et al. Tirosine kinase rearrangements in Ph-negative acute lymphoblastic leukemia - a FISH approach. EHA learning center; 2018. 216176 Abstract.

30. Moorman A, Barretta E, Kirkwood A, Schwab C, Creasey T, Patrick P, et al. Comprehensive screening of B-other adult ALL patients treated on UKALL14 estimates frequency and prognostic impact of gene alterations and identifies JAK-STAT abnormalities as markers of poor outcome. EHA learning center; 2018. 214532 Abstract.

31. Russell $\sqcup$, Capasso M, Vater I, Akasaka T, Bernard OA, Calasanz MJ, et al. Deregulated expression of cytokine receptor gene, CRLF2, is involved in lymphoid transformation in B-cell precursor acute lymphoblastic leukemia. Blood. 2009;114(13):2688-98.

32. Buitenkamp TD, Pieters R, Gallimore NE, van der Veer A, Meijerink JP, Beverloo HB, et al. Outcome in children with Down's syndrome and acute lymphoblastic leukemia: role of IKZF1 deletions and CRLF2 aberrations. Leukemia. 2012;26(10):2204-11.

33. Ferrari A, Vitali S, Ghelli Luserna Di Rora A, Baldazzi C, Testoni N, Robustelli V, et al. Unexpected high rate of known and unknown rearrangements in adult triple negative acute lymphoblastic leukemia identified thanks to a efficient transcriptome four tool pipeline analysis. EHA library; 2020. 294277 abstract.

34. Chen IM, Harvey RC, Mullighan CG, Gastier-Foster J, Wharton W, Kang H, et al. Outcome modeling with CRLF2, IKZF1, JAK, and minimal residual disease in pediatric acute lymphoblastic leukemia: a Children's oncology group study. Blood. 2012;119(15):3512-22.

35. Harvey RC, Mullighan CG, Chen IM, Wharton W, Mikhail FM, Carroll AJ, et al. Rearrangement of CRLF2 is associated with mutation of JAK kinases, alteration of IKZF1, Hispanic/Latino ethnicity, and a poor outcome in pediatric B-progenitor acute lymphoblastic leukemia. Blood. 2010;115(26): 5312-21.

36. Konoplev S, Lu X, Konopleva M, Jain N, Ouyang J, Goswami M, et al. CRLF2positive B-cell acute lymphoblastic leukemia in adult patients: a singleinstitution experience. Am J Clin Pathol. 2017;147(4):357-63.
37. Yoda A, Yoda Y, Chiaretti S, Bar-Natan M, Mani K, Rodig SJ, et al. Functional screening identifies CRLF2 in precursor B-cell acute lymphoblastic leukemia. Proc Natl Acad Sci U S A. 2010;107(1):252-7.

38. Parsa C, Thompson A, Orlando R, Rupani R, Guo J. Novel KMT2A-ATP5L gene fusion in a young adult with rapidly progressive Ph-like $t(9 ; 12)$ acute $B$ lymphoblastic leukemia. Hum Pathol. 2020;20:200359.

39. Heatley SL, Sadras T, Kok CH, Nievergall E, Quek K, Dang P, et al. High prevalence of relapse in children with Philadelphia-like acute lymphoblastic leukemia despite risk-adapted treatment. Haematologica. 2017;102(12): e490-3.

40. Goekbuget N, Beck J, Brueggemann M, Burmeister T, Buss EC, Frickhofen N, et al. Moderate intensive chemotherapy including CNS-prophylaxis with liposomal Cytarabine is feasible and effective in older patients with $\mathrm{Ph}$ negative acute lymphoblastic leukemia (ALL): results of a prospective trial from the German multicenter study Group for Adult ALL (GMALL). Blood. 2012;120:1493.

41. Roberts KG, Gu Z, Payne-Turner D, McCastlain K, Harvey RC, Chen IM, et al. High frequency and poor outcome of Philadelphia chromosome-like acute lymphoblastic leukemia in adults. J Clin Oncol. 2017;35(4):394-401.

42. Stock W, Luger SM, Advani AS, Yin J, Harvey RC, Mullighan CG, et al. A pediatric regimen for older adolescents and young adults with acute lymphoblastic leukemia: results of CALGB 10403. Blood. 2019;133(14):154859

43. Cario G, Leoni V, Conter V, Attarbaschi A, Zaliova M, Sramkova L. Relapses and treatment-related events contributed equally to poor prognosis in children with ABL-class fusion positive B-cell acute lymphoblastic leukemia treated according to AIEOP-BFM protocols. Haematologica. 2020;105(7): 1887-94.

\section{Publisher's Note}

Springer Nature remains neutral with regard to jurisdictional claims in published maps and institutional affiliations.

Ready to submit your research? Choose BMC and benefit from:

- fast, convenient online submission

- thorough peer review by experienced researchers in your field

- rapid publication on acceptance

- support for research data, including large and complex data types

- gold Open Access which fosters wider collaboration and increased citations

- maximum visibility for your research: over $100 \mathrm{M}$ website views per year

At $\mathrm{BMC}$, research is always in progress.

Learn more biomedcentral.com/submissions 